\title{
Towards periodic and time-referenced flood risk assessment using airborne remote sensing
}

\author{
Claire Brenner*, Claude Meisch, Benjamin Apperl, Karsten Schulz \\ University of Natural Resources and Life Sciences, Vienna, Institute of Water Management, Hydrology and Hydraulic Engineering \\ (IWHW), Muthgasse 18, 1190 Vienna, Austria. \\ *Corresponding author. Tel.: +43 147654 5515. E-mail: claire.brenner@boku.ac.at
}

\begin{abstract}
Flood risk management is founded on the regular assessment of damage potential. A significant parameter for assessing damage potential is the number of at-risk objects. However, data sets on exposure are often incomplete and/or lack time-references. Airborne remote sensing data, such as orthophotos, offers a regularly-updated, time-referenced depiction of land use. As such, remote sensing data compensates for incomplete data sources (such as digital cadastral maps). Orthophotos can even be used to analyze the temporal dynamics of flood damage potential, providing that timereferenced information is available for multiple time points. This paper describes a method for integrating orthophotos into flood risk analyses. In Austria, orthophotos are updated every three years, allowing their integration into cyclical flood risk assessments. The results of a case study presented in this paper demonstrate that orthophotos are most useful where other data sources, such as digital cadastral maps, are incomplete. In such situations, orthophotos lead to a significant increase in estimated damage potential. Orthophoto analysis allows damage potentials to be re-assessed at regular intervals, another major advantage over digital cadastral maps. Orthophoto analysis thus supports the evaluation of flood risk management options.
\end{abstract}

Keywords: Flood risk management; Damage potential analysis; Object-based image analysis; Orthophoto analysis; Building detection.

\section{INTRODUCTION}

Recurrent flooding events along the Danube can have catastrophic consequences and cause heavy damage. Reasons for this degree of severity can be found in the dense settlement exposed to floods alongside streams. As lifelines, riverside settlements flourish through advantages like trading routes, fertile soils and economic development. An estimated one billion people worldwide currently live in floodplains (Di Baldassarre et al., 2013). Despite large investments in structural flood protection, flood damage in Europe has increased (Barredo, 2009; UNISDR, 2011). However, the increase in damages cannot be traced back to an increasing probability of extreme events alone, but also back to an increasing vulnerability of affected areas (Blöschl et al., 2015; Cammerer and Thieken, 2013; Hartmann et al., 2013).

Consequently, the implementation of the EU Floods Directive (FD, EG, 2007) has progressively changed from structural measures to integral flood risk management focusing on precautionary, remedial, and awareness-raising measures (Thieken et al., 2007). The FD calls for cyclically recurring (1) flood risk assessment (2), the compilation of hazard and risk maps, and (3) the development of flood risk management plans. Every six years, all of the cycle's individual steps are repeated (see Fig. 1) and all information on flood risk updated. The regular assessment and evaluation of conditions should enable future-oriented planning and help fulfill the goals of the FD to reduce the negative consequences of flooding and to avoid increases in damage potential.

In order to conduct a recurring damage potential assessment, up-to-date data on the flood hazard in, and the vulnerability of, affected areas is required. Data on flood hazard includes information on flood extent and inundation depths for events with known return periods (de Moel et al., 2009). Vulnerability is determined by land use and is a product of exposure (the quan-

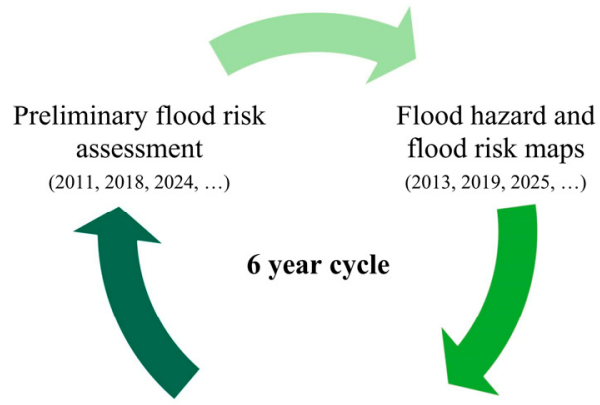

Flood risk

management plans

$(2015,2021,2027, \ldots)$

Fig. 1. Six-year cycle for carrying out the EU Floods Directive.

tity of at-risk objects) and the susceptibility of at-risk objects to flooding (Merz and Thieken, 2004). Through changes in the exposure and in the predominant susceptibility, damage potentials exhibit a temporal variability. Thus, vulnerability needs to be considered as dynamic/non-static measurement to account for changes in the quantity of at-risk objects. Therefore, in order to draw conclusions on how the damage potential will develop long-term and in compliance with cyclic flood risk assessment, data must exist for multiple time points and be regularly updated.

Yet, time-referenced and up-to-date data sets for flood risk assessment are scarce, increasing the uncertainty in flood risk management. In general, digital cadastral maps (DCM) provide GIS-based information on existing property development and typically serve as base map for the assessment of at-risk objects. However, the entry of objects into the national DCM is not mandatory in Austria. This creates significant discrepancies between objects marked in the DCM and the actual object inventory in some areas. New objects are integrated into the 
DCM one at a time, as they are reported. Therefore, DCM's do not depict development at a specific point in time as they hold no time-referenced information. For this reason, the DCM alone does not offer a complete assessment of at-risk objects and cannot depict a development trend. Using the DCM as the only reference for assessing exposure can cause the damage potential to be significantly underestimated. Based on this dilemma, Nachtnebel and Apperl (2013) recommend using orthophotos to identify changes in land use and property development in flood hazard areas, as these images are time-referenced and more current.

In cases like these, remote sensing information can make a positive contribution to flood risk assessment by adding valuable information on either flood hazard or vulnerability. Here, remote sensing data can improve the pool of available data and help compensate for the deficits of other available data sources, for example the lack of time referenced information in digital cadastral maps.

While remote sensing data has also been used to improve the assessment of flood hazard (Dorn et al., 2014; Sanyal and Lu, 2004; Schumann et al., 2007; van der Sande et al., 2003; Zazo et al., 2015), this study focuses on remote sensing data as input for the assessment of exposure of at-risk objects in the flood zone for different points in time.

Remote sensing techniques comprise a variety of sensors with different spatial and temporal resolutions as well as spectral properties. Even though methods for building detection based on aerial imagery alone exist (Cretu and Payeur, 2013; Dare, 2005), building detection is often based on a combination of different remote sensing data sets, such as a combination of high resolution optical imagery and laser scan data (Aguilar et al., 2013; Hermosilla et al., 2011; Rottensteiner et al., 2007; Sanyal and Lu, 2005; Taubenböck et al., 2011; Vu et al., 2009; Wegner et al., 2011).

Airborne laser scan data provide object height as valuable piece of information, which allows objects that protrude from the Earth's surface to be recognized. However, a drawback of laser scan data in flood risk management in Austria is that laser scan data is neither collected on a regular basis nor for the entire national territory. In contrast, orthophotos are collected every three years, favoring their integration into cyclical flood risk assessment.

In several studies, aerial imagery was analyzed to detect atrisk objects on small spatial scale where a DCM is missing or is not up-to-date (de Risi et al., 2013a, b; Leone et al., 2011; Vojtek and Vojteková, 2016). However most of these orthophoto analyses for flood vulnerability assessment are done with little degree of automatisation.

In order to make orthophoto analysis applicable to larger regions, a modular method for building extraction is introduced to enhance the assessment of vulnerability in the flood zone. The main objective of this paper is to assess the value of this method for integrating remote sensing data (orthophotos) into flood risk analysis and damage potential assessment. Accordingly, the method is tested in two municipalities in Upper Austria for which damage potentials are assessed based on the information gleaned from the orthophoto analysis.

Following this objective, the paper first gives a short overview on available data sources for flood risk assessment in Austria, before entering a detailed description of the method using orthophotos to identify at-risk objects. Furthermore, the implementation of the updated data set into the damage potential assessment is described. Then, the results of the two municipalities are discussed. Finally, the conclusion summarizes key findings.

\section{MATERIALS AND METHODS Study area}

The developed method was tested in two municipalities, Kremsmünster and Perg in Upper Austria. The location of the case study areas within Austria are depicted in Fig. 2. Both communities are categorized as Areas of Potential Significant Flood Risk (APSFR, FD). Kremsmünster, with a population of 6538 inhabitants (2016) and an area of $42.14 \mathrm{~km}^{2}$, is situated adjacent to the river Krems on a fluival terrace and exhibits potentially significant flood risk.

Perg, a community of $26.46 \mathrm{~km}^{2}$ with a population of 8272 inhabitants, is situated in the drained meadow next to the regulated river Naarn. Perg was exposed to major flooding events in 1954 and 2002 which caused large economic damage and the necessity for encompassing infrastructural restoration.

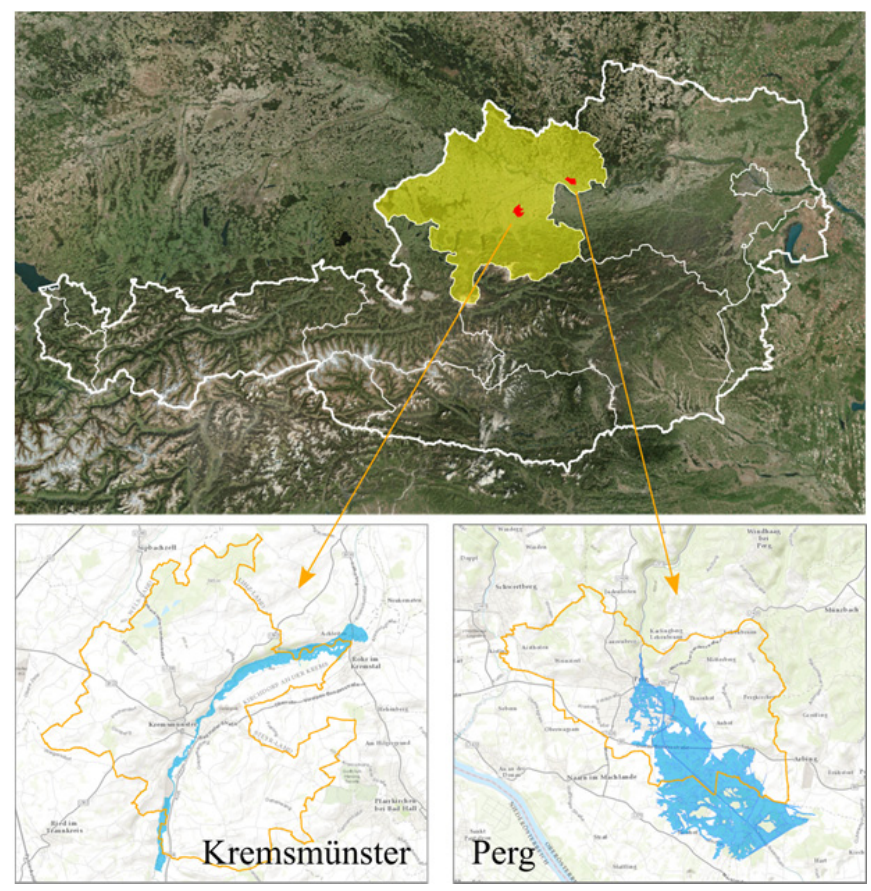

Fig. 2. Location of the two case study areas, Kremsmünster and Perg.

\section{Data}

Flood damage potential is defined as the maximal potential damage that can occur due to a flood event with a given return period (BMLFUW, 2006). Hence, the damage potential describes a maximum value of expected negative consequences under given flood conditions. As a consequence, GIS-based data on flood hazard as well as vulnerability are needed for flood risk assessment. Thus the DCM, zoning maps and maps of flood zone area and depths for flood events at 30-, 100-, and 300 -year return periods $\left(\mathrm{HQ}_{30}, \mathrm{HQ}_{100}, \mathrm{HQ}_{300}\right)$ were employed in the course of this assessment. The DCM was kindly provided by the Upper Austrian state. The zoning maps are freely available in the Upper Austrian Digital Geographic Informationsystem (DORIS, 2015). Flood zone areas and depths were extracted from the governmental data record on floods, provided by the BMLFUW, which is a consolidation of the natural hazard overview and risk assessment Austria (HORA) and detailed hydraulic simulations.

The Federal Office of Metrology and Surveying (BEV, 2015) collects orthophotos (aerial images) of the entire Austrian 
national territory every three years. These orthophotos provide a distortion-free and true-to-scale map of the Earth's surface. Since 2010, the ground resolution of orthophotos is $0.20 \mathrm{~m}$ (previously $0.25 \mathrm{~m}$ ) and is therefore higher than comparable satellite data, which has a maximum resolution of $0.5 \mathrm{~m}$. Orthophotos were also kindly provided by the Upper Austrian state.

\section{Methodology}

The described method is based on an object-based image analysis, which has been developed over the past several years as a new way of thematically analyzing remote sensing images compared to pixel-by-pixel analysis (Blaschke et al., 2008). The advantage of object-based image analysis is that it considers contextual information such as size, form and texture, in addition to information from the electromagnetic spectrum, and thus leads to significant improvements in land use classification in urban areas (Kressler et al., 2005; Myint et al., 2011).

Fig. 3 shows a schematic representation of the selected workflow for extracting information on existing property development from orthophotos as well as further work steps for assessing damage potentials. The individual work steps of the orthophoto analysis are explained in the following subsections.

\section{Removal of green areas}

The first step of the workflow is to remove green areas in order to reduce the number of calculations necessary to process large image sections at this resolution. Green areas comprise all green hued image elements, which mainly represent grassy areas, meadows and forests. These areas (image elements with low vulnerability) are not considered further in the analysis. If color infrared images (CIR) are available, vegetation can be separated from other image elements through indices such as the Normalized Difference Vegetation Index (NDVI) which is based on the ratio between reflection in the near-infrared and the visible spectral ranges (Carlson and Ripley, 1997; Myneni et al., 1995; Tucker et al., 2005). The authors of the present

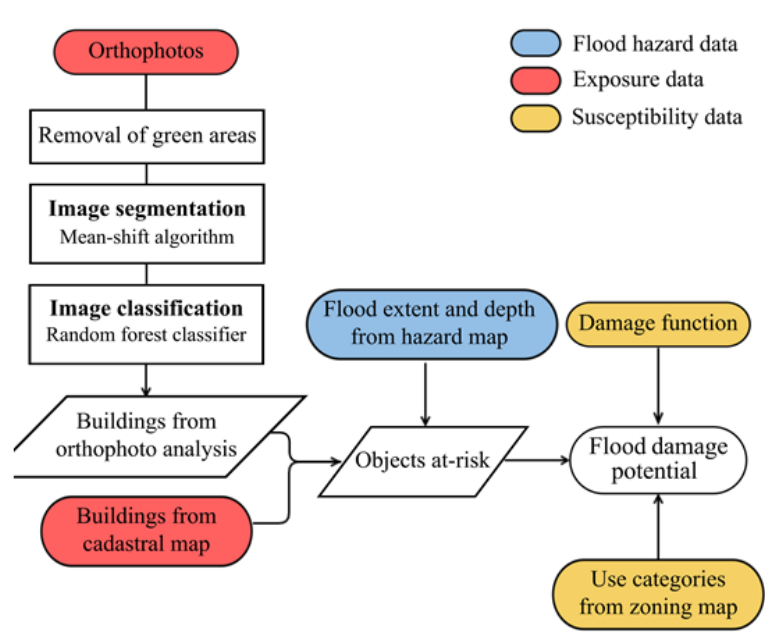

Fig. 3. The workflow starts with processing the orthophotos: removal of green areas, image segmentation and classification. Objects/segments classified as buildings are input into the subsequent flood damage potential assessment. Property development information from orthophoto analysis and digital cadastral maps, as well as information on flood extent and inundation depth are combined to identify at-risk objects. Use-dependent damage functions link these at-risk objects to the monetary flood damage potential.

study used orthochromatic images with three bands in blue, green and red spectral ranges (RGB). In order to simplify the removal of green image areas from orthochromatic images, the color spectrum is transformed from RGB to HSV. In the HSV color spectrum, pixel colors are described as triplets, in this case hue, saturation, and value. Color settings in the HSV color spectrum are closer to the color perception of the human eye than is the case for the RGB spectrum. This allows objects that appear green to the human eye to be more easily differentiated from other objects. Pixels with hue between 60 and 180 and a minimal saturation of 0.125 were removed from the images. Fig. 4a) shows a segment of an orthophoto including existing developments, streets, and green areas. Fig. 4b) shows the resulting image after the removal of green areas.
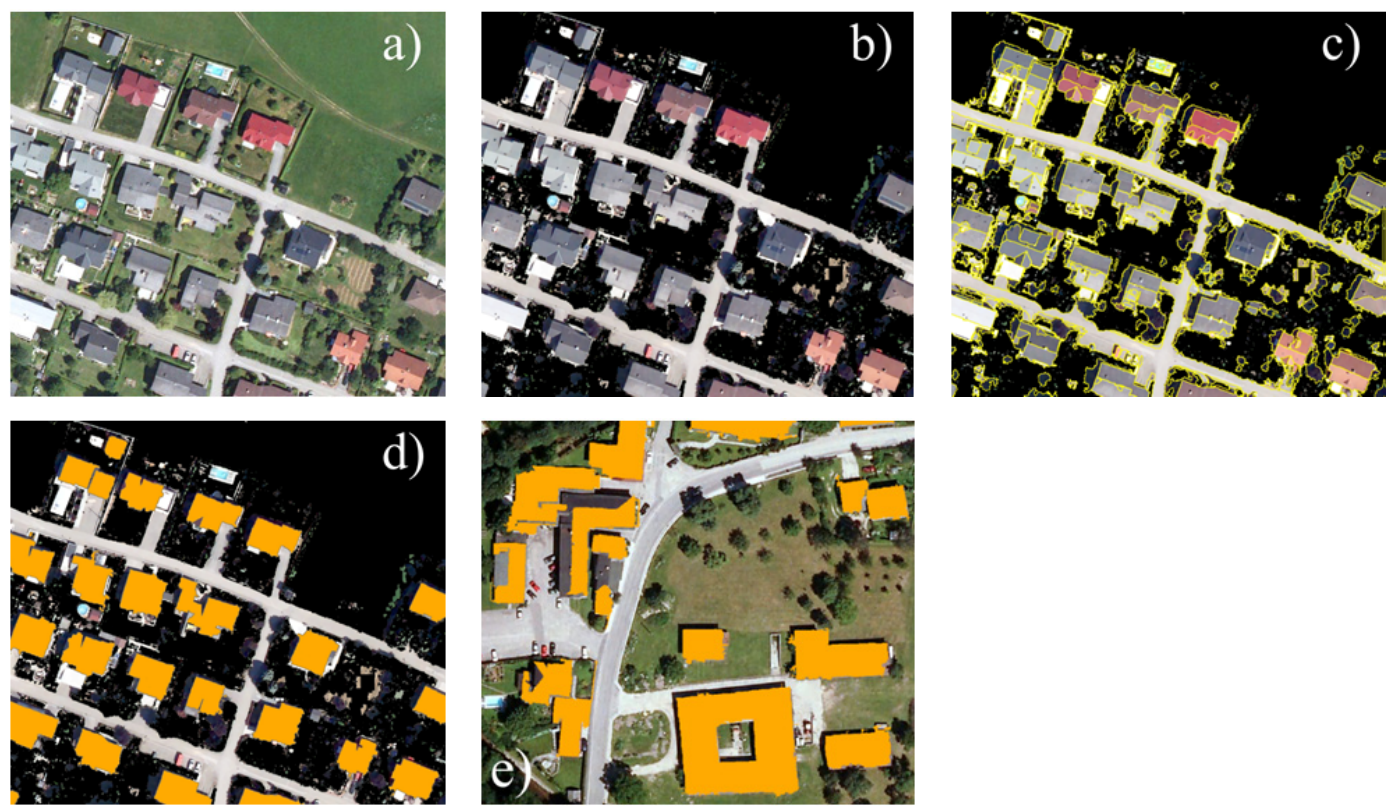

Fig. 4. Assessing property development using orthophotos. Each image shown is the result of a different work step: Area segment in risk zone (a), orthophoto after green areas removed (b), results of segmentation (c), results of building classification (d), effect of shadows (e). 
Towards periodic and time-referenced flood risk assessment using airborne remote sensing

\section{Image Segmentation}

Image segmentation seeks to group the similar spectral elements of neighboring pixels. The advantage of segmentation is that subsequent classification is not exclusively based on the color properties of the pixels but also on shape parameters. In this way, shape characteristics of segments such as area, perimeter and their related ratios are used to distinguish use classifications. Various algorithms are available for segmentation and object-based classification of high-resolution images. These algorithms are implemented in both commercial and opensource software packages. One of the most frequently used commercial software packages is Definiens Developer (previously known as eCognition) from the software producer Definiens Imaging GmbH (Baatz et al., 2000; Benz et al., 2004). Blaschke (2010) analyzed scientific research projects in the field of OBIA and concluded that eCognition was used in more than $50 \%$ of all projects using OBIA techniques. An opensource alternative is Orfeo Toolbox from the French Space Agency (CNES) (Inglada and Christophe, 2009). Orfeo Toolbox possesses an independent user interface and can also be used as a plugin to QGIS, an open-source geographic information system. The research presented in this paper was conducted using Orfeo Toolbox open-source software.

Segmentation is based on the mean-shift algorithm (Cheng, 1995; Comaniciu and Meer, 2002; Fukunaga and Hostetler, 1975), a non-parametric analysis technique for locating the maxima of a density function. The advantage of this algorithm is that no a-priori knowledge is necessary of the number and shape of the sought segments.

Segmentation produces segments in vector form, which are distinguished by their similar spectral features. Orfeo Toolbox was specifically designed to process large (satellite) image data sets. As such, special focus in the implementation of the mean shift algorithm was placed on the processability of large data sets. The user defines two parameters: the radiometric range distance that is related to the support of the kernels and optionally a maximum spatial distance, which must not be exceeded within one segment. The selection of a suitable value for both parameters depends on the question at hand and on the size and homogeneity of the objects being sought. As a rule, the smaller the selected values for both parameters, the smaller the separated segments. In this study the two user-defined parameters were both set to 15 . The already pre-processed orthophotos (green areas removed) were divided into segments using the described process. In Fig. 4c), the yellow lines represent the dividing lines of individual segments. It should be noted that roof areas are mostly divided into more than one segment - sunny and shady sides of the roof.

\section{Image classification}

Image classification builds on the results of segmentation. As is the case for segmentation, a variety of algorithms are available for image classification. For example, rule-based approaches or various machine-learning methods can be applied. Regardless of method (except for novel approaches like convolutional neural networks), the next step is to determine the segments' color and shape parameters. In the case of shape, parameters include area, perimeter, short and long axes, and minimum object width. Based on these basic parameters, additional ratios are generated. In the case of color values, the parameters average, variance, and mode are calculated for the three bands of the RGB space for each segment, as well as ratios between these bands.
The analysis workflow applies an ensemble classification method, "the random forest" algorithm. The principle of the "random forest" comes from Breiman (2001) and deals with an ensemble of decision trees. The idea behind ensemble methods is to improve classification quality by averaging the results of multiple algorithms or calculations (Dietterich, 2000). A decision tree breaks inputs into increasingly smaller subsets at each internal node of the tree. Eventually, at the lowest level, each leaf node corresponds to a unique path through the decision tree and specifies a class. In the "random forest" method, many decision trees are created simultaneously and used for classification. The final result of the classification process is the most frequently predicted class from all decision trees. This method requires the creation of a training set. In the training set, individual segments are attributed to a known class. Linking between segment properties and user-assigned classes creates the basis for supervised machine learning. Segment features are used along the nodes of the decision tree to gradually differentiate data into individual classes. For this study, ten land use classes, including red, white and gray roof areas (facilities and buildings), fields, grassy areas, forests, streets, shaded areas, swimming pools and bodies of water were differentiated. Subsequent analysis of the damage potential considers only use classes that represent buildings and facilities. Damages to fields, grassy areas, and forests are disregarded.

The final product of image classification is a data set which depicts the existing property development within a selected area, separated out from other land uses (see Fig. 4d).

As Fig. 4e) shows, in some cases building areas are not correctly classified in full due to the effect of shadows. In general, buildings and facilities with red roof areas are more robustly identified than buildings with gray roofs. This can be traced back to the similar spectral properties of gray roof areas and, for example, parking areas and streets In order to keep the negative effects of incomplete object area recognition to a minimum when assessing damage potential, the recognized building areas are intersected with the digital cadastral map (DCM) in a post-processing step. In areas where objects overlap in both data sets, the building area from the DCM is assumed. This has the advantage of only accounting for differences between the data sets where objects have been added or removed. Thus, objects that exist in both data sets, but with different building areas, do not lead to any alterations in the calculated damage potential. The updated information on exposure can be used further to estimate the damage potential.

\section{Damage potential analyses}

The following steps are necessary for damage potential assessment, regardless of the type of data used to determine existing development. For this reason they are only described briefly here. The entire process of assessing damage potential is detailed in Fig. 3.

Existing property development is a significant input value for evaluating the vulnerability of regions endangered by flooding. The number of at-risk objects during a flood event determines exposure. The degree of vulnerability of these at-risk objects to a flood event depends on their use. In order to determine use, the recorded development is intersected with the zoning map so that each building can be attributed to a use category (Nachtnebel and Apperl, 2013; Neuhold and Nachtnebel, 2012; Schulz and Schwingshandl, 2014). Usederived damage functions are applied in order to calculate the monetary damage potential. The degree of detail applied in differentiating use categories therefore depends on the damage 
functions used in further work steps. It should be noted that the choice of damage function considerably influences the results of the damage potential assessment, as well as causes large fluctuation ranges for the calculated monetary damage potential when comparing multiple damage functions (Huttenlau et al., 2015).

When choosing a damage function to calculate damage values, researchers have their choice of area-based functions or object-based functions. The commonly used BUWAL approach, which was also applied in this study, is based on analyses of the Swiss Federal Office for the Environment (FOEN, 1999). The approach involves a step function that determines the affected area's damage value per square meter (unit damage value) depending on inundation depth and use category (see Table 1). Original damage values per square meter recommended by BUWAL were adapted to Austrian conditions and discounted to the year 2014 (Nachtnebel and Apperl, 2014).

Table 1. Damage function BUWAL (FOEN, 1999) adapted to Austria conditions and discounted to the net present value (Nachtnebel and Apperl, 2014).

\begin{tabular}{lccc}
\hline Use category & $\begin{array}{c}\text { Inundation depth } \\
<=0.5 \mathrm{~m}\end{array}$ & $\begin{array}{c}\text { Inundation depth } \\
>0.5 \mathrm{~m}\end{array}$ & Unit \\
\hline $\begin{array}{l}\text { Semi-/detached } \\
\text { buildings }\end{array}$ & 127 & 750 & $€ / \mathrm{m}^{2}$ \\
\hline $\begin{array}{l}\text { Apartment } \\
\text { buildings }\end{array}$ & 150 & 829 & $€ / \mathrm{m}^{2}$ \\
\hline $\begin{array}{l}\text { Commercial } \\
\text { buildings }\end{array}$ & 434 & 1975 & $€ / \mathrm{m}^{2}$ \\
\hline $\begin{array}{l}\text { Industrial } \\
\text { buildings }\end{array}$ & 529 & 2765 & $€ / \mathrm{m}^{2}$ \\
\hline Stables/ barns & 87 & 415 & $€ / \mathrm{m}^{2}$ \\
\hline Warehouses & 16 & 162 & $€ / \mathrm{m}^{2}$ \\
\hline
\end{tabular}

With this type of approach, the affected area of at-risk objects influences the calculated damage potential significantly. Two possibilities exist for determining which areas are affected. (1) Any object, which is situated wholly or partially within a flood zone, is considered in full. (2) Only the portion of the object's area, which is actually situated in the flood zone, is considered in the damage potential analysis. Taking this into consideration, this study differentiated between industrial and residential buildings. For residential buildings, the entire building was considered in the damage potential analysis, whereas for industrial buildings, only the portion of the building actually situated in the flood zone was taken into account. This differentiation is justified, as the danger of flooding is generally not considered when planning the layout of residential buildings. If, for example, only a small portion of a building is affected by flooding, but this portion contains important facilities or infrastructure, damage can be significant. In contrast, it can be assumed that for industrial buildings certain flood safety precautions have been taken, placing sensitive or valuable infrastructure and equipment in areas outside the flood zone. However, dealing with businesses and industry when analyzing damage potential is difficult in general, particularly when using unit damage values. In these cases, large sector-specific discrepancies can be expected. Nachtnebel and Apperl (2015) and Gocht et al. (2009) discuss using the capital intensity of various regional commercial activity classes as one possible approach for better depicting the damage potential of industrial facilities.

\section{RESULTS \& DISCUSSION}

For both case study areas, Perg and Kremsmünster, the assessment of existing development was based on the analysis of orthophotos taken in 2001,2006, and 2010. The orthophotos were analyzed according to the previously described workflow in order to extract information on existing development.

\section{Kremsmünster}

Fig. 5 shows an overview of the study area, the flood zone, and the affected buildings and facilities during a flood event with a 300-year return period. When comparing the actual building inventory (as of the year 2010) to the object inventory in the DCM (as of 10/2013), two areas of the municipality show particularly visible discrepancies. Buildings from the orthophoto analysis are marked in orange. The building inventory from the DCM - shown in yellow - is overlaid on top of the orthophoto building inventory. Any still-visible orange buildings (i.e. not covered by yellow buildings) were not assessed by the DCM. This means that these buildings are only found in the orthophotos and not in other data sets. In the case of such a flood event, the number of affected objects would be significantly underestimated without the use of remote sensing methods. Underestimating affected building areas has a direct impact on the monetary analysis of damage potential.

Fig. 6a) compares the calculated damage potential using only buildings in the DCM to the results of the analysis of 2010 orthophotos for $\mathrm{HQ}_{30}, \mathrm{HQ}_{100}$ and $\mathrm{HQ}_{300}$ events. As the return period of the considered events increases, the difference

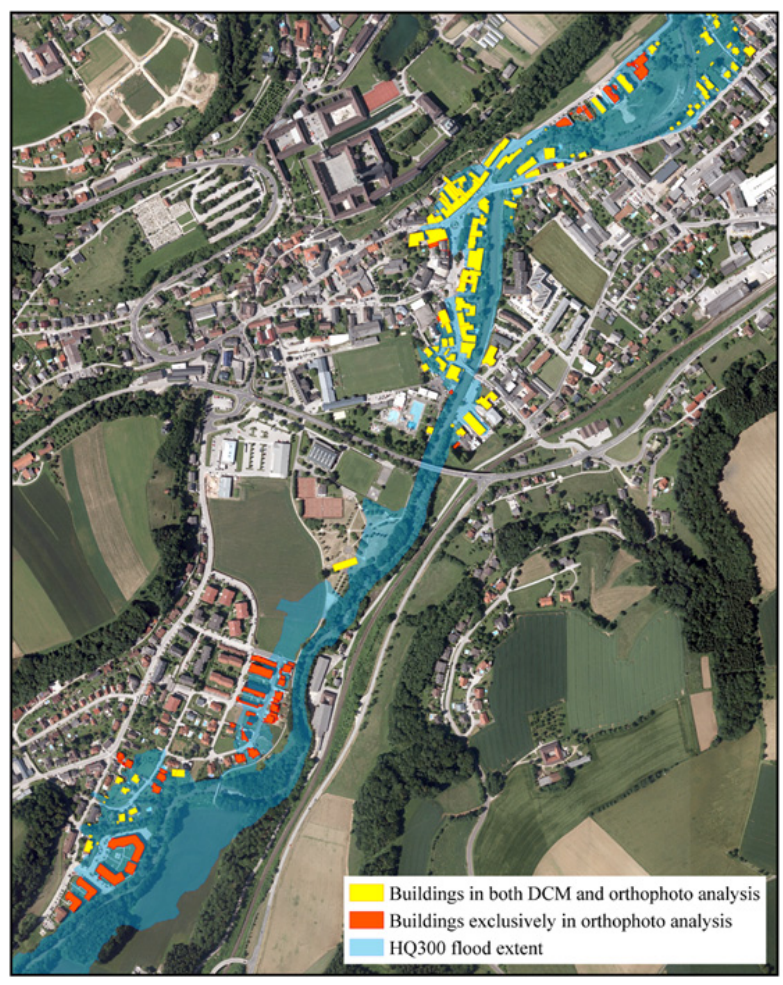

Fig. 5. Overview of the flood extent for a $\mathrm{HQ}_{300}$ event and assessed objects at-risk in the municipality of Kremsmünster. The orthophoto analysis (depicted in orange) is overlaid with the digital cadastral map, DCM (depicted in yellow). Still-visible orange buildings were not assessed by the DCM. Thus the number of affected objects would be significantly underestimated for a $\mathrm{HQ}_{300}$ flood event. 

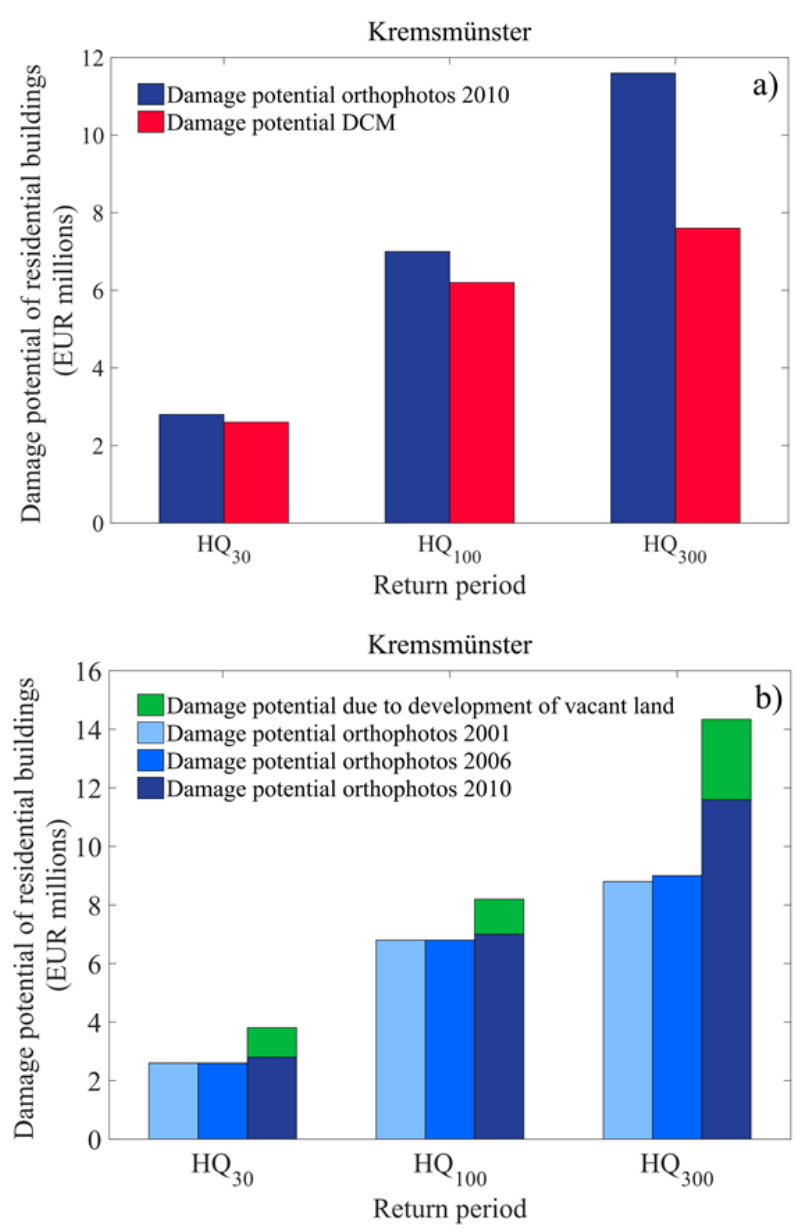

Fig. 6. Comparison of damage potentials based on existing development found through orthophoto analysis (2010) and from the cadastral map in the municipality of Kremsmünster (a). Development of damage potential between 2001 and 2010 in the case study area Kremsmünster (blue bars). The green bar atop the dark blue bar (damage potential according to orthophotos 2010), anticipates a possible future increase of damage potential due to the development of vacant land (suitable for building) in the flood zone. This estimate is based on the analysis of vacant land and an average building density in the study area (b).

between the calculated damage potential with and without the inclusion of remote sensing data grows. For an $\mathrm{HQ}_{300}$ event, the inclusion of orthophoto analysis led to a $50 \%$ increase in the damage potential as compared to the damage potential based on DCM data. This discrepancy can be traced back to the fact that buildings not recorded by the DCM are mostly found in the $\mathrm{HQ}_{300}$ flood zone. As floods very rarely occur in the $\mathrm{HQ}_{300}$ flood zone, risk awareness is low. Nevertheless, development in this area inevitably leads to an increased risk of flood damage. According to the Technical Guidelines for the Federal Water Construction (RIWA-T, 2006), the goal should be to protect residential developments and significant economic and transportation infrastructure from flood events with a 100-year return period. Extreme flood events with discharges beyond $\mathrm{HQ}_{100}$, such as the floods of 2002 and 2013, have led to flooding catastrophes despite protective measures. Therefore, the inclusion of these zones in damage potential assessments and regional development considerations are crucial.

Fig. $6 \mathrm{~b}$ compares damage potentials for three points in time and shows stronger increases in damage potential for events with higher return periods. Increases were higher in the time period 2006 to 2010 than 2001 to 2006 .
In order to be able to estimate the potential for future property development, still existing vacant land within the flood zone was identified. This was accomplished by overlaying zoning maps, DCM, and orthophotos. Unoccupied land suitable for property development was classified as non-built up, vacant land. Identified vacant land can be used as an indicator for possible future development. If there is no vacant land in flood zones, the possibility for future development is limited and hence so is the creation of new potentially at-risk objects. If, in the depicted areas, vacant land remains, future development should be anticipated. In order to estimate the increase in damage potential due to the future development of vacant land, a link between vacant land and building floor areas is needed. This link was established by calculating an average building density per use category based on existing development in the flood zone. The product of vacant land suitable for development and building density allows possible future increases in at-risk object areas and thus damage potential to be estimated. Fig. 6b) shows the effect of developing vacant land on future damage potentials. Dark blue bars indicate damage potentials derived by analyzing 2010 orthophotos. The green bars atop the blue bars represent an estimate of how much the damage potential would increase due to the development of still existing vacant land in the study area.

\section{Perg}

In the municipality of Perg, the $\mathrm{HQ}_{300}$ flood zone extends far into the core development area. However, as shown in Fig. 7,

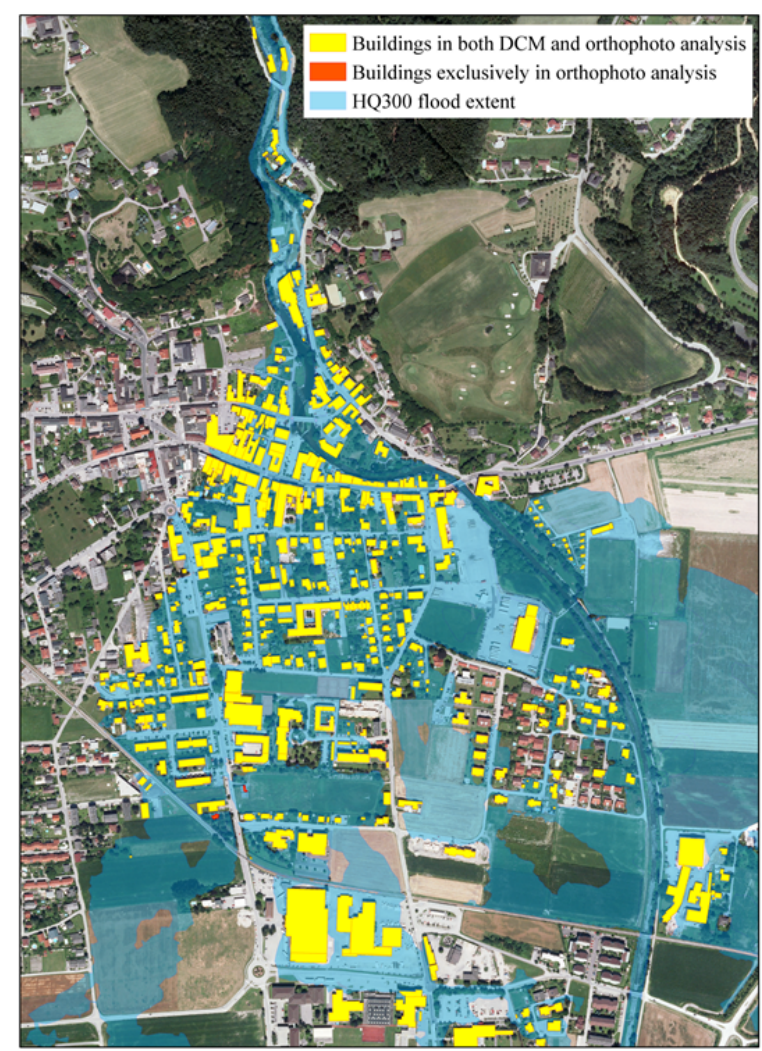

Fig. 7. Overview of the flood extent for a $\mathrm{HQ}_{300}$ event and assessed objects at-risk in the municipality of Perg. The orthophoto analysis (depicted in orange) is overlaid with the digital cadastral map, DCM (depicted in yellow). It is apparent that the DCM accurately depicts existing property development in the flood zone. Thus information gain due to orthophoto analyses is low in this case. 
the DCM accurately depicts development in the flood zone. As in Fig. 5, building inventory from the DCM - shown in yellow - is overlaid on top of the orthophoto building inventory. Only two buildings which were not marked in the DCM were detected in the orthophoto analysis. Furthermore, the DCM contains two objects in the flood zone which do not exist in the actual building inventory. Thus the DCM overestimates the number of at-risk objects in this study area. Fig. 8a) shows the comparison of damage potentials calculated from DCM information only and analysis of 2010 orthophotos. It is apparent that both approaches lead to nearly the same damage potential estimates. Additionally, only small changes in land use and in the number of at-risk objects occurred during the period under review in the municipality of Perg. Fig. 8b) shows the development of damage potential from 2001 to 2010 and the effect of possible development of vacant land on damage potential.

The very stable number of at-risk objects and damage potential over the analyzed time period 2001 to 2010 could indicate a lack of available vacant land for ongoing property development. However, as shown in Fig. 8b), vacant land still exists in the flood zone.
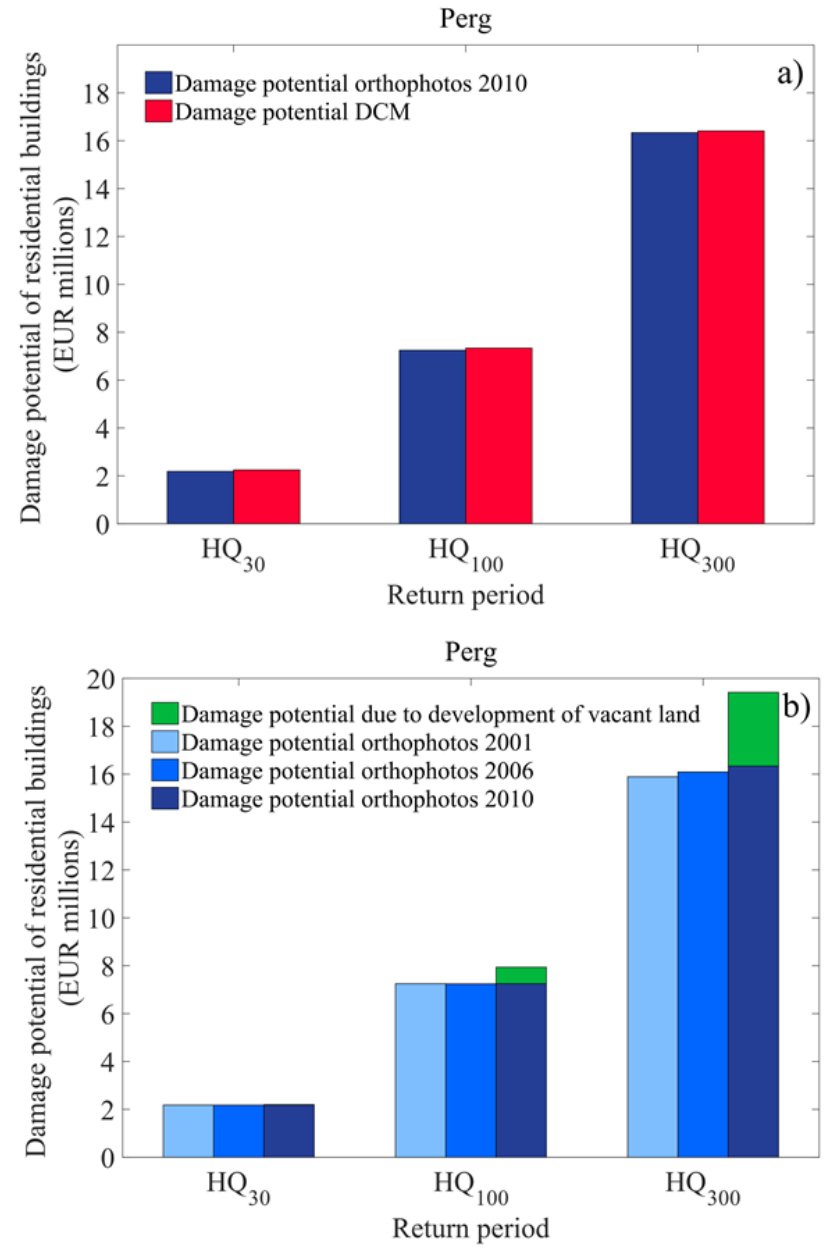

Fig. 8. Comparison of damage potentials based on existing development found through orthophoto analysis (2010) and from the cadastral map in the municipality of Perg (a). Development of damage potential between 2001 and 2010 in the case study area Perg (blue bars). The green bar atop the dark blue bar (damage potential according to orthophotos 2010), anticipates a possible future increase of damage potential due to the development of vacant land (suitable for building) in the flood zone. This estimate is based on the analysis of vacant land and an average building density in the study area (b).

\section{Discussion}

The results for Kremsmünster clearly show the advantage of integrating orthophotos into damage potential analysis. Due to their time-referenced and periodic acquisition, orthophotos not only enhance estimates of current damage potentials, but also allow the damage potential to be analyzed at regular intervals. Thus past property development in flood hazard areas becomes visible, which in turn can help to assess possible future trends.

The assessment of existing property development using remote sensing images led to a considerable change in the calculated damage potential. The gain in information through orthophoto analysis is particularly apparent in this example, as the other available data source (DCM) did not completely capture all existing development in the case study municipality. The Kremsmünster study compared the results of damage potential analyses for three points in time $(2001,2006,2010)$ and studied the changes in damage potential.

As Fig. 6b) shows, the damage potential increased most significantly for an $\mathrm{HQ}_{300}$ between 2006 and 2010 (light to dark blue bars). Within this time span, damage potential increased by about $30 \%$ from the 2006 value. This can be linked to successive property development. Fig. 9 compares a segment of the study area at the three specified points in time and shows the successive development in the flood zone. Fig. 9 also shows that vacant land does exist in the analyzed flood zones. The development of this land would result in an enhanced damage potential. Fig. $6 \mathrm{~b}$ shows that the increase in damage potential due to the development of vacant land amounts to about $20 \%$ of the value from 2010 for a flood event with a return period of 300 years.

In the municipality of Perg the DCM accurately depicts property development (see Fig. 7) and consequently builds a good data basis for the assessment of at-risk objects in the flood zone. Thus, information gains resulting from remote sensing techniques are modest in this case.

In the flood zone exists vacant land that could potentially raise future damage potentials in this zone. However, due to little dynamics in property development in the past (see Fig. 8b), it is questionable if existing vacant land will be used for further property development in the near future.

The results of the two case studies show that the integration of remotely sensed data can considerably improve the pool of data for flood risk assessment and are especially beneficial where other data sources, such as digital cadastral maps, are incomplete. The case study also makes plain that remotesensing data, which is regularly updated and time-referenced, presents an informational gain in comparison to relying solely on information contained in DCM, zoning maps and other geodata as dynamics in property development become visible.

In the municipality of Perg orthophoto analysis led to damage potentials similar to those calculated based on DCM information only. However, in Kremsmünster the use of orthophotos for the assessment of at-risk objects increased calculated damage potentials significantly.

As the quality of the DCM is not known beforehand, the integration of orthophotos into flood risk assessment seems worthwhile and reasonable.

Alongside orthophotos, other remote sensing data sets are available for analyzing damage potential. For example, airborne laser scan data can be used to create a three-dimensional image of the earth's surface. However, as discussed before, laser scan data is neither acquired periodically nor systematically for the entire Austrian national territory. This complicates the embedding of laser scan analysis in a cyclic and regular assessment of 

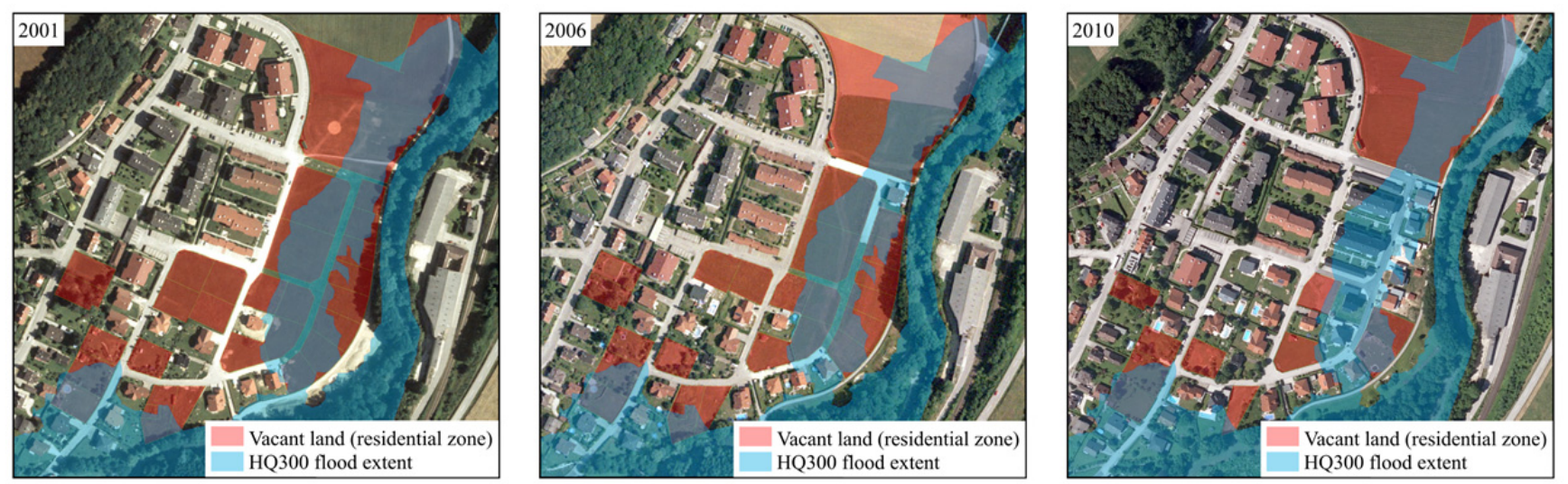

Fig. 9. Comparison of orthophotos taken between 2001 and 2010 in an area of the Kremsmünster municipality where development has increased from year to year. The red areas indicate vacant land in residential zones.

damage potential and its trends. Thus, this study aimed at developing a workflow for the detection of objects at-risk relying on orthophotos only without the need for other not readily available remote sensing data.

High-resolution satellite data (such as data from the European space aeronautics' Pleiades satellite) are also available as a further alternative source of information. Using satellite data can achieve high-temporal resolution for analysis, despite a somewhat lower spatial resolution.

In the future, an additional valuable source of data will become available, namely the Land Information System Austria (LISA) (Banko et al., 2014). LISA also builds upon orthophoto analysis, as well as satellite and laser scan data. It also produces an image of land cover including development. As of October 2015, results are available for Austrian urban agglomerations. Eventually, comprehensive land use will be imaged for the entire national territory and updated on a three-year cycle.

\section{CONCLUSIONS}

Orthophotos present a time-referenced depiction of an area's land use. As such, if images taken at various points in time are available, past developments in land use can be analyzed. Such analyses of past trends allow conclusions to be drawn about development in the future.

The type of information gleaned from such an analysis can support decision makers in planning suitable flood risk reduction measures and avoiding the development of new risks. The goal of the EU Floods Directive is to protect Europe's people, environment, and cultural heritage, as well as its tangible assets. In order to reach this goal, regular analysis and estimation of the current risks and dynamics of damage potential in flood zones is necessary. This paper presents a method developed to assess property development in flood hazard zones using highresolution aerial images (orthophotos). The analysis of orthophotos allows a periodic and routine survey of development at regular intervals of time. This method can partially compensate for other less up-to-date data sources (for example digital cadastral maps) and increase the reliability of damage potential assessments.

The analysis of orthophotos is based on object-based image analysis, which comprises of two basic work steps: image segmentation and image classification. During image segmentation, the image is sub-divided into areas of homogeneous (color) properties. During the final image classification step, the newly divided segments are classified into various land use categories such as buildings, streets, bodies of water, etc. based on color and shape properties.

Intersecting flood zones and depths with development data allows the damage potential to be assessed. The monetary damage potential can be calculated using use-derived damage functions. By comparing images taken at various points in time, researchers can assess past changes in regional development and corresponding damage potentials, as well as draw conclusions on potential future development.

This study tested the described method in two case study regions. In one of the regions, the digital cadastral map's assessment of development was found to be fairly comprehensive. The use of orthophotos in this region, the Perg municipality, led to few changes in the calculated damage potential. In the other region, the Kremsmünster municipality, the digital cadastral map's assessment of development was incomplete. In this case, the advantages of integrating orthophotos into the damage analysis were significant. Orthophoto assessment led to a $50 \%$ increase in the assessed damage potential for a flood event with a 300-year return period. For the same flood event, the past damage potential increased by approximately $30 \%$ between 2006 and 2010. This increase can be attributed to a gradual development of vacant land in the flood zone. As long as vacant land that is suitable for building exists, further increases in damage potential due to the development of these areas can be anticipated.

The goal of a follow-up study, which is currently in-progress and builds on the results of this project, is to review the regional applicability of the method. A further goal is to quantify the reliability of building recognition using the methods described here. In the new study, the work sequence (developed here for test regions) is applied to a spatially larger region and the feasibility of regionalization is evaluated. In contrast to studies were orthophotos are analyzed manually, the proposed method should facilitate orthophoto analysis at a regional level.

A key issue in flood risk management is assessing the current state of damage potential and its trends, which heavily depend on the exposure of at-risk objects. Thus, it is crucial to have an accurate depiction of land use. Both regional and national flood risk management requires a large-scale overview of flood risk. The DCM is not uniformly up-to-date across all regions; however it is more accurate in some areas than in others. Thus, orthophotos are an invaluable source of information in flood risk management planning as they allow a regular and systematic analysis of land use and an assessment of at-risk objects in flood zones. Applying this method at a 
regional level therefore could help identify regional "hotspots" of damage potential with higher reliability. Results from this extended analysis can be used to create risk management plans, as well as contribute to an informed evaluation of different courses of action.

Acknowledgement. The work has been carried out under the project "Development in floodplain areas - land use and effectiveness of measures" funded by the Upper Austrian Government.

\section{REFERENCES}

Aguilar, M. a, Saldana, M.M., Aguilar, F.J., 2013. GeoEye-1 and WorldView-2 pan-sharpened imagery for object-based classification in urban environments. International Journal of Remote Sensing, 34, 7, 2583-2606.

Baatz, M., Schäpe, A., Strobl, J., Blaschke, T., Griesebner, G., 2000. Multiresolution Segmentation - an optimization approach for high quality multi-scale image segmentation. Angewandte Geographische Informationsverarbeitung, 12, 12-23. Retrieved from internal-pdf://xn--baatz_schpe_20003891068462-jkc/Baatz_Sch?pe_2000.PDF

Banko, G., Mansberger, R., Gallaun, H., Grillmayer, R., Prüller, R., Riedl, M., Stemberger, W., Steinnocher, K., Walli, A., 2014. Land Information System Austria (LISA). In: Manakos, I., Braun, M. (Eds.): Land Use and Land Cover Mapping in Europe. Springer, 18, pp. 237-254.

Barredo, J.I., 2009. Normalised flood losses in Europe: 1970-2006. Natural Hazards and Earth System Science, 9, 1, 97-104.

Benz, U.C., Hofmann, P., Willhauck, G., Lingenfelder, I., Heynen, M., 2004. Multi-resolution, object-oriented fuzzy analysis of remote sensing data for GIS-ready information. ISPRS Journal of Photogrammetry and Remote Sensing, 58, 3-4, 239-258.

$\mathrm{BEV}, 2015$. Fernerkundung-Folder. [Brochure of the remote sensing products of the BEV]. Retrieved from http://www.bev.gv.at/pls/portal/docs/page/bev_portal_conte nt_allgemein/0200_produkte/pdf-doku/fernerkundungfolder.pdf (In German.)

Blaschke, T., 2010. Object based image analysis for remote sensing. ISPRS Journal of Photogrammetry and Remote Sensing, 65, 1, 2-16.

Blaschke, T., Lang, S., Hay, G.J., 2008. Object-Based Image Analysis. Spatial Concepts for Knowledge-Driven Remote Sensing Applications, 418. http://doi.org/10.1007/978-3540-88183-4

Blöschl, G., Gaál, L., Hall, J., Kiss, A., Komma, J., Nester, T., Parajka, J., Perdigão, R. A. P., Plavcová, L., Rogger, M., Salinas, J. L., Vigkione, A., 2015. Increasing river floods: fiction or reality? WIREs Water. http://doi.org/10.1002/wat2.1079

BMLFUW, 2006. Hochwasserzonierung Austria - HORA. Wien. Retrieved from http://www.bmlfuw.gv.at/wasser/schutz vor naturgefahren/ beratung_information/hora02.html (In German.)

Breiman, L., 2001. Random forests. Machine Learning, 45, 5-32.

Cammerer, H., Thieken, A.H., 2013. Historical development and future outlook of the flood damage potential of residential areas in the Alpine Lech Valley (Austria) between 1971 and 2030. Regional Environmental Change, 13, 5, 999-1012.

Carlson, T.N., Ripley, D.A., 1997. On the relation between NDVI, fractional vegetation cover, and leaf area index. Remote Sensing of Environment, 62, 3, 241-252.
Cheng, Y., 1995. Mean Shift, Mode Seeking, and Clustering. IEEE Transactions on Pattern Analysis and Machine Intelligence, 17, 8,. http://doi.org/0162-8828/95\$04.00

Comaniciu, D., Meer, P., 2002. Mean shift: A robust approach toward feature space analysis. IEEE Transactions on Pattern Analysis and Machine Intelligence, 24, 5, 603-619.

Cretu, A.-M., Payeur, P., 2013. Building Detection in Aerial Images Based on Watershed and Visual Attention Feature Descriptors. In: 2013 International Conference on Computer and Robot Vision, IEEE, Regina, CA, pp. 265-272.

Dare, P.M., 2005. Shadow analysis in high-resolution satellite imagery of urban areas. Photogrammetric Engineering \& Remote Sensing, 71, 2, 169-177.

de Moel, H., van Alphen, J., Aerts, J.C.J.H., 2009. Flood maps in Europe - methods, availability and use. Natural Hazards and Earth System Science, 9, 2, 289-301.

de Risi, R., Jalayer, F., de Paola, F., Iervolino, I., Giugni, M., Topa, M.E., Mbuya, E., Kyessi, A., Manfredi, G., Gasparini, P., 2013a. Flood risk assessment for informal settlements. Natural Hazards, 69, 1, 1003-1032.

de Risi, R., Jalayer, F., Manfredi, G., Carozza, S., 2013 b. VISK: a GIS-compatible platform for micro-scale assessment of flooding risk un urban areas. In: 4th ECCOMAS Thematic Conference on Computational Methods in Structural Dynamics and Earthquake Engineering, COMPDYN, Kos Island, Greece.

Di Baldassarre, G., Viglione, A., Carr, G., Kuil, L., Salinas, J. L., Blöschl, G., 2013. Socio-hydrology: Conceptualising human-flood interactions. Hydrology and Earth System Sciences, 17, 8, 3295-3303.

Dietterich, T.G., 2000. Ensemble methods in machine learning. Multiple Classifier Systems, 1857, 1-15.

DORIS, 2015. Digital Upper Austrian spatial information system. Data available under http://doris.ooe.gv.at

Dorn, H., Vetter, M., Höfle, B., 2014. GIS-based roughness derivation for flood simulations: A comparison of orthophotos, LiDAR and Crowdsourced Geodata. Remote Sensing, 6, 2, 1739-1759.

EG, 2007. Directive 2007/60/EC of the European Parliament and of the Council of 23 October 2007 on the assessment and management of flood risks. European Commision, Brussels, pp. 27-34.

FOEN, 1999. Risikoanalyse bei gravitativen Naturgefahren Umwelt-Materialien. [Risk analysis for natural hazards.]. Vol. 107. Schweizerische Eidgenossenschaft, Bern. (In German.)

Fukunaga, K., Hostetler, L., 1975. The estimation of the gradient of a density function, with applications in pattern recognition. IEEE Transactions on Information Theory, 21, 1, 32-40.

Gocht, M., Schröter, K., Ostrowski, M., Rubin, C., 2009. EWASE - Early Warning Systems Efficiency - risk assessment and efficiency analysis. Water, 136-137.

Hartmann, D.L., Klein Tank, A.M.G., Rusticucci, M., Alexander, L. V. , Brönnimann, S., Charabi, Y., Dentener, F.J., Dlugokencky, E.J., Easterling, D.R., Kaplan, A., Soden, B.J., Thorne, P.W., Wild, M., Zhai, P.M., 2013. Observations: Atmosphere and Surface, in The Physical Science Basis. In: Stocker, T.F., Qin, G.-K.P.D. (Eds.): Contribution of Working Group I to the Fifth Assessment Report of the Intergovernmental Panel on Climate Change. Cambridge University Press, Cambridge, United Kingdom and New York, NY, USA.

Hermosilla, T., Ruiz, L.A., Recio, J.A., Estornell, J., 2011. Evaluation of automatic building detection approaches 
combining high resolution images and LiDAR data. Remote Sensing, 3, 12, 1188-1210. http://doi.org/10.3390/rs3061188

Huttenlau, M., Schneeberger, B., Winter, B., Reiss, J., Stötter, J., 2015. Analysis of the loss probability relation on a community level: a contribution to a comprehensive flood risk assessment. In: Sener, S.M., Brebbia, C.A., Ozcevik, O. (Eds.): Disaster Management and Human Health Risk IV WIT Press, Southhampton, UK, pp. 171-182.

Inglada, J., Christophe, E., 2009. The Orfeo Toolbox remote sensing image processing software. In: IEEE International Geoscience and Remote Sensing Symposium, IEEE, Cape Town, SA, pp. 733-736.

Kressler, F.P., Steinnocher, K., Franzen, M., 2005. Objectoriented classification of orthophotos to support update of spatial databases. In: International Geoscience and Remote Sensing Symposium, 1, C, IEEE, Seoul, KR, pp. 253-256.

Leone, F., Lavigne, F., Paris, R., Denain, J.C., Vinet, F., 2011. A spatial analysis of the December 26th, 2004 tsunamiinduced damages: Lessons learned for a better risk assessment integrating buildings vulnerability. Applied Geography, 31, 1, 363-375.

Merz, B., Thieken, A.H., 2004. Flood risk analysis: Concepts and challenges. Österreichische Wasser- und Abfallwirtschaft, 56, 3-4, 27-34.

Myint, S.W., Gober, P., Brazel, A., Grossman-Clarke, S., Weng, Q., 2011. Per-pixel vs. object-based classification of urban land cover extraction using high spatial resolution imagery. Remote Sensing of Environment, 115, 5, 11451161. http://doi.org/10.1016/j.rse.2010.12.017

Myneni, R.B., Hall, F.G., Sellers, P.J., Marshak, A.L., 1995. Interpretation of spectral vegetation indexes. IEEE Transactions on Geoscience and Remote Sensing, 33, 2, 481-486. http://doi.org/10.1109/36.377948

Nachtnebel, H., Apperl, B., 2013. Wasserwirtschaftliche Entwicklung in Überflutungsgebieten: Instumentenevaluierungsstudie. [Development in flood prone areas: assessment of flood management alternatives]. IWHW BOKU, Vienna. (In German.)

Nachtnebel, H., Apperl, B., 2014. Hochwasserrisikomanagementplan Gleisdorf. Pilotprojekt zur Umsetzung der EU-Hochwasserrichtlinie. [Flood risk management and emergency plan for the city of Gleisdorf (Styria)]. IWHW BOKU, Vienna. (In German.)

Nachtnebel, H., Apperl, B., 2015. Beurteilung des HochwasserSchadenspotenzials unter dynamischen Bedingungen. Österreichische Wasser- Und Abfallwirtschaft, 67, 3-4, 120-130.

Neuhold, C., Nachtnebel, H., 2012. Beurteilung des Hochwasserrisikos: Skalenaspekte und Umsetzung. [Assessing flood risk: Aspects of scale and implementation]. Österreichische Wasser- und Abfallwirtschaft, 64, 5-6, 323328. (In German.)

RIWA-T, 2006. Technische Richtlinie für die Bundeswasserbauverwaltung. [Technical Guidelines for the Federal Water Construction]. Austrian Ministry for Agriculture, Forestry, Environment and Water Management, Vienna. (In German.)

Rottensteiner, F., Trinder, J., Clode, S., Kubik, K., 2007. Building detection by fusion of airborne laser scanner data and multi-spectral images: Performance evaluation and sensitivity analysis. ISPRS Journal of Photogrammetry and Remote Sensing, 62, 2, 135-149.
Sanyal, J., Lu, X.X., 2004. Application of remote sensing in flood management with special reference to monsoon Asia: A review. Natural Hazards, 33, 283-301.

Sanyal, J., Lu, X.X., 2005. Remote sensing and GIS-based flood vulnerability assessment of human settlements: A case study of Gangetic West Bengal, India. Hydrological Processes, 19, 18, 3699-3716.

Schulz, K., Schwingshandl, A., 2014. Wasserwirtschaftliche Entwicklung in Überflutungsgebieten - Raumnutzung und Maßnahmenwirkung. [Development in floodplain areas land use and effectiveness of measures]. IWHW BOKU \& riocom, Vienna. (In German.)

Schumann, G., Matgen, P., Hoffmann, L., Hostache, R., Pappenberger, F., Pfister, L., 2007. Deriving distributed roughness values from satellite radar data for flood inundation modelling. Journal of Hydrology, 344, 1-2, 96111.

Taubenböck, H., Wurm, M., Netzband, M., Zwenzner, H., Roth, A., Rahman, A., Dech, S., 2011. Flood risks in urbanized areas - Multi-sensoral approaches using remotely sensed data for risk assessment. Natural Hazards and Earth System Science, 11, 2, 431-444.

Thieken, A.H., Kreibich, H., Müller, M., Merz, B., 2007. Coping with floods: preparedness, response and recovery of flood-affected residents in Germany in 2002. Hydrological Sciences Journal, 52, 5, 1016-1037.

Tucker, C.J., Pinzon, J.E., Brown, M.E., Slayback, D.A., Pak, E.W., Mahoney, R., Vermote, E.F., El Saleous, N., 2005. An extended AVHRR 8-km NDVI dataset compatible with MODIS and SPOT vegetation NDVI data. International Journal of Remote Sensing, 26, 20, 4485-4498.

UNISDR, 2011. Global Assessment Report on Disaster Risk Reduction: Revealing Risk, Redefining Development. United Nations, Geneve, $178 \mathrm{p}$.

van der Sande, C.J., de Jong, S.M., de Roo, A.P.J., 2003. A segmentation and classification approach of IKONOS-2 imagery for land cover mapping to assist flood risk and flood damage assessment. International Journal of Applied Earth Observation and Geoinformation, 4, 3, 217-229.

Vojtek, M., Vojteková, J., 2016. Flood hazard and flood risk assessment at the local spatial scale: a case study. Geomatics, Natural Hazards and Risk, (in press). http://doi.org/10.1080/19475705.2016.1166874

Vu, T.T., Yamazaki, F., Matsuoka, M., 2009. Multi-scale solution for building extraction from LiDAR and image data. International Journal of Applied Earth Observation and Geoinformation, 11, 4, 281-289.

Wegner, J.D., Hänsch, R., Thiele, A., Sörgel, U., 2011. Building detection from one orthophoto and high-resolution InSAR data using conditional random fields. IEEE Journal of Selected Topics in Applied Earth Observations and Remote Sensing, 4, 1, 83-91.

Zazo, S., Molina, J.L., Rodriguez-Gonzalvez, P., 2015. Analysis of flood modeling through innovative geomatic methods. Journal of Hydrology, 524, 522-537.

Received 1 December 2015 Accepted 25 May 2016 